\title{
Isolated myoclonic alien hand as the sole presentation of pathologically established Creutzfeldt-Jakob disease: a report of two patients
}

\author{
D J L MacGowan, N Delanty, F Petito, M Edgar, J Mastrianni, S J DeArmond
}

\begin{abstract}
Creutzfeldt-Jakob disease may have many atypical presentations before the development of classic progressive dementia and startle myoclonus. In two patients with pathologically established disease association with a progressive alien hand syndrome was the sole initial manifestation of the disease.
\end{abstract}

(F Neurol Neurosurg Psychiatry 1997;63:404-407)

Keywords: alien hand; Creutzfeldt-Jakob disease; clinical presentation

The alien hand sign, or "main etrangere", was first described by Brion and Jedynak ${ }^{1}$ as a combination of involuntary, seemingly purposeful, hand movements with denial of its ownership in three patients with corpus callosal tumours. The term "diagonistic dyspraxia" was coined earlier by Akelaitis ${ }^{2}$ in a patient with a corpus callosotomy who developed transient, involuntary antagonistic movements of the nondominant hand which interfered with attempted voluntary movements of the dominant hand. Bogen ${ }^{3}$ further defined this entity in the non-dominant hand after surgical anterior callosotomy and used the term intermanual conflict. Subsequent reports of dominant alien hand sign as a presentation of anterior cerebral artery infarction involving both the corpus callosum and dominant medial frontal cortex ${ }^{4-11}$ led to the concept of two different kinds of alien hand, one "frontal" in the dominant hand and the other "callosal" in the non-dominant hand. The frontal type was associated with reflex grasping, motor perseveration, and compulsive manipulation of tools. This structural, lesion based, disconnectionist approach has been challenged recently by a strong association with corticobasal ganglionic degeneration ${ }^{12}$ and two case reports of pathologically established Alzheimer's disease presenting with isolated alien hand. ${ }^{13} 14$

We now report two patients with pathologically established Creutzfeldt-Jakob disease who presented with alien hand complaints in the absence of clinically obvious dementia. This is the first report of this association and gives further support to the concept that the alien hand is an interesting syndrome with numerous causes but is not a clinically useful localising sign. It also adds to the protean list of presenting features of Creutzfeldt-Jakob disease. ${ }^{16}$

\section{Case 1}

A 78 year old previously healthy, right handed white woman with no relevant medical or family history was referred with a six week history of a tremulous, jerky , "wandering" left hand which she could not control and complained, "seemed to have a life of its own". She had no cognitive complaints.

On examination, she was in no acute distress and her language, attention, orientation and memory, including a mini mental test, were all normal. She had a mild left spastic hemiparesis with severe cortical sensory loss. Proprioception was absent to the hips and shoulders, resulting in severe sensory ataxia and pseudoathetosis. The left arm was noted to have spontaneous movements which often appeared purposeful and antagonised voluntary movements of her right arm. There was frequent spontaneous and stimulus sensitive myoclonus in the left hand and foot. She did not deny ownership of her left hand but said it had a purpose unto itself and felt "foreign", particularly when it would wander out of her view. In the absence of visual input she could not identify her own hand from the examiner's. She also exhibited pronounced intermanual conflict with bimanual tasks such as manipulating her spectacles. Her gait was limited by the hemiparesis, ataxia, and myoclonus. Brain and cervical spine MRI were uninformative and routine laboratory tests and a spinal tap with cytology of the CSF were all negative. An EEG showed right hemispheric slowing with periodic complexes, raising the possibility of a prion disorder. Over the ensuing month, the patient progressively deteriorated with disorientation, global memory loss, and diffuse startle myoclonus. The patient's alien hand progressed to the point where she could not locate it and would deny it as her own. It would grab her throat or hit her in the face and she usually limited its activity by holding it in her right 
hand's grasp. Her dementia and myoclonus rapidly progressed along with the development of bilateral $1 \mathrm{~Hz}$ periodic complexes with triphasic waves on the EEG. Genomic DNA was extracted from peripheral leucocytes and the prion protein $(\operatorname{PrP})$ gene was amplified using the polymerase chain reaction. Denaturing gradient gel electrophoresis ${ }^{15}$ was used to screen the entire open reading frame of the PrP gene and did not show any mutation. The codon 129 of this gene was homozygous for methionine. A brain biopsy was not performed and she died six months later from acute bronchopneumonia and pulmonary emboli.

The formalin fixed brain weighed $1180 \mathrm{~g}$ and was grossly normal. Microscopical analysis with standard haematoxylin and eosin and Luxol fast blue stain showed neuronal loss with conspicuous spongiosis and reactive astrocytosis in the cerebral isocortex, neostriatum, diencephalon (particularly the mamillary bodies), the periaqueductal and medullary tegmental grey, and the red, tectal, gracile, and inferior olivary nuclei. Of note, neuritic (senile) plaques were present in the cerebral isocortex but not in Ammon's horn. There were also no neurofibrillary tangles, granuolovacuolar degeneration, or Hirano bodies. The neuropathological diagnosis was spongiform encephalopathy consistent with Creutzfeldt-Jakob disease.

\section{Case 2}

A 74 year old right handed white woman with no relevant medical or family history was referred with a seven week history of progressive weakness, jerking, and incoordination of her left arm and leg. She noticed the first symptom in her left hand which "would not do what she wanted it to do" but would jerk for no reason and interfere with the actions of her right hand during daily activities such as dressing and eating. Occasionally, her left hand performed involuntary purposeful actions such as unbuttoning her blouse and removing a hair pin. These symptoms came on over one week but soon weakness, ataxia, and myoclonus involved the left leg, such that she was no longer ambulatory after one month. By the time of presentation to our hospital, she had become unaware of the identity of her left arm and her right arm had developed mild weakness and occasional jerks. She had no cognitive complaints.

On examination, her orientation, concentration, language and memory, including a mini mental assessment, were normal. Her left hand had spontaneous and stimulus sensitive myoclonus, and performed uncontrolled semipurposeful grasping movements at her blouse, face, and right hand. There was also a grasp and palmomental reflex. Similar, but much less frequent myoclonus was noted in the right hand. She had no voluntary control of her left hand and denied it as her own. She regarded the left hand with great suspicion and treated it as a hostile entity. When asked to name the owner of her left hand, she could not say but was certain that it was not her own. She had a supranuclear left facial and palatal weakness. There was a spastic tetraparesis affecting the left side more than the right. Sensory testing disclosed intact responses to pin prick bilaterally but with alloaesthesia on the left arm. Proprioception was absent in the left arm and leg and absent to the knee and elbow on the right. Despite intact visual fields, she had a dense left visual neglect by line bisection and construction tasks. She was unable to stand unaided due to the severe weakness, myoclonus, and sensory ataxia.

Routine laboratory tests and results of examination of CSF were all normal. Brain MRI with gadolinium showed normal age related changes. Three days after admission, she deteriorated, becoming obtunded and showing pronounced bilateral startle myoclonus. An EEG disclosed a low amplitude background with diffuse delta slowing and generalised periodic $1-2 \mathrm{~Hz}$ complexes. Ten days later, radioimmunoassay for the presence of 14-3-3 protein in CSF using polyclonal rabbit anti 14-3-3 $\beta$ (courtesy of $M$ Harrington, Caltech University) was positive. The demonstration of this normal human brain protein in the CSF of a patient with clinical dementia is $96 \%$ sensitive and specific for the diagnosis of Creutzfeld-Jakob disease. ${ }^{17}$ Consequently a brain biopsy was not performed and the patient was managed with comfort care. She died in a hospice 12 weeks after the onset of the illness.

The brain weight was not recorded but generalised mild gyral atrophy was noted. At microscopy, typical widespread spongiform change with reactive astrocytosis was noted in the frontoparietal cortices and diencephalic structures, but was absent on sections of the brain stem, cerebellum, and spinal cord. The figure shows that the histoblot technique for in situ detection of protease resistant PrP, performed as previously described, ${ }^{18}$ was positive, but immunostaining of formalin fixed sections with $\alpha-\operatorname{PrP}$ antibodies did not show PrPamyloid plaques. Genomic DNA was extracted from brain tissue and the PrP gene amplified using the same technique as in case 1 . Denaturing gradient gel electrophoresis did not show any mutation and the codon 129 status was heterozygous, methionine/valine.

\section{Discussion}

Alien hand has not been previously reported as a presenting feature of Creutzfeldt-Jakob disease. ${ }^{16}$ Both patients presented with a non-dominant myoclonic alien hand with cortical sensory loss and a progressive spastic hemiparesis in the absence of clinically demonstrable dementia or generalised myoclonus. This clinical syndrome is identical to that of corticobasal ganglionic degeneration as described by Rinne et al, ${ }^{12}$ Riley et $a l,{ }^{19}$ and Gibb et $a l,{ }^{20}$ apart from the duration of the illness in corticobasal ganglionic degeneration which ranges from four to eight years. ${ }^{12}$ In the largest series, by Rinne et al, alien hand complaints were present in 14 of the 36 patients and took on average a year to develop after symptoms first started. This contrasts with our two patients who first complained of an alien hand and then developed a rapidly progressive 


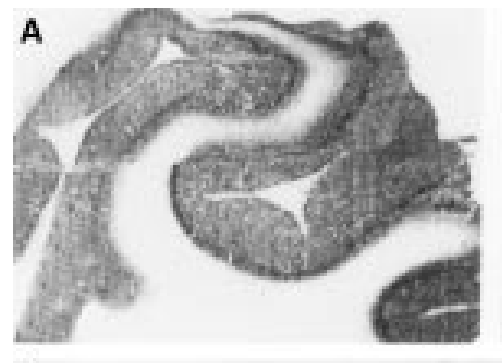

B

C

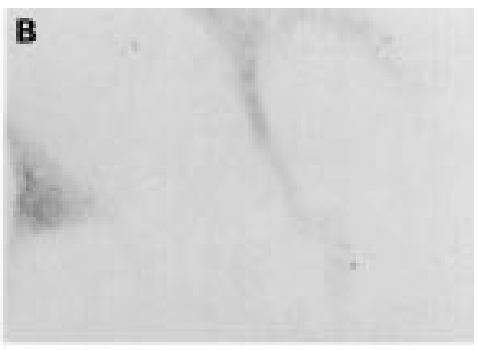

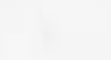

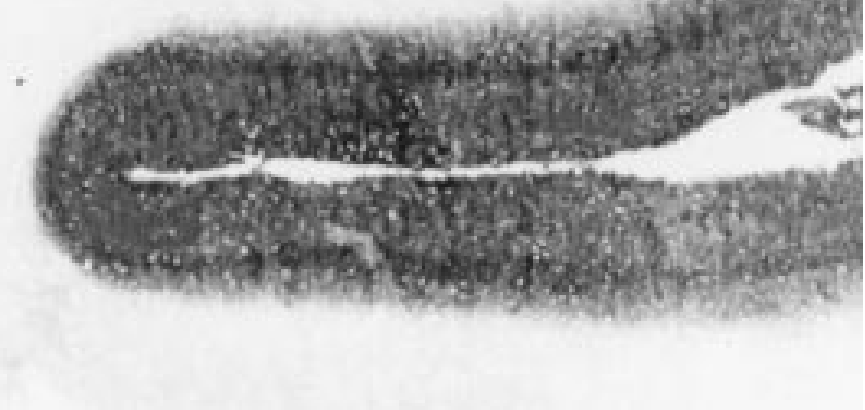

Histoblot of frontal cortex testing immunoreactivity for the protease resistant form of $\operatorname{PrP}(\operatorname{PrPSC})$ with the human PrP-specific monoclonal antibody, 3F4. Low $(A)$ and high (C) magnification views of frontal cortex from case 2 are compared with that from a subject without prion disease (B). bilateral motor and supplementary motor areas through transcallosal information transfer. This may also explain the absence of an alien hand in an ambidextrous man with an otherwise complete callosal disconnexion syndrome due to haemorrhage in the body of the corpus callosum. ${ }^{23}$ The other two right handed patients with callosal haemorrhage in this report had a prominent non-dominant alien hand.

Selective injury to the mesial frontal area, genu, and body of the corpus callosum does not explain the reported cases of alien hand due to posterior lesions and the frequent cortical sensory loss seen in both of our cases and those due to Alzheimer's disease ${ }^{13}{ }^{14}$ and corticobasal ganglionic degeneration. ${ }^{12}{ }^{19-21}$ Posterior or sensory lesions include a left parietal surgical encephalomalacia, ${ }^{26}$ right parietal cortical infarction, ${ }^{825}$ right precommunal posterior cerebral artery infarction involving the thalamus, splenium of the corpus callosum, and occipital lobe, ${ }^{27}$ and thalamocapsular haemorrhage. ${ }^{28}$ Clearly, the alien hand cannot be explained by callosal disconnexion theories alone.

Decety et $a l^{9}$ have attempted to replicate the movements of an alien hand using PET imaging of normal right handed subjects observing a "virtual" right hand grasping a series of three dimensional objects. Subjects were instructed to watch the hand "as if it were their own". This paradigm was compared with imagining grasping the objects with their own right hand. A control rest period was also recorded. Observing the "virtual" hand movements differed by activation of the extrastriate visual association areas and cerebellar hemispheres bilaterally, implying the importance of these centres for motor learning. The active motor imagery of the patient's own right hand stimulated, as expected, areas known to be related to motor preparation and programming including the motor cortices (area 6) bilaterally and left premotor areas. It may be that the clinical alien hand represents a release phenomenon resulting from processes interfering with the coordinated function of motor execution and motor learning.

It seems clear that the alien hand is a poorly localising, often non-specific "sign" and is more accurately regarded as a syndrome. This syndrome may arise from injury to centres governing praxis and motor planning as well as those concerning proprioceptive sensation and spatial localisation of the involved hand. This injury may be due to a discrete structural lesion but the absence of this suggests a degenerative disorder. This is most commonly corticobasal ganglionic degeneration or Alzheimer's disease. This report adds Creutzfeldt-Jakob disease to the list of disorders for consideration. A rapid evolution of symptoms with progressive myoclonus suggests a prion disorder. Mental deterioration was not an initial presenting feature in our patients as in $15 \%$ of Brown's series of 234 sporadic cases with Creutzfeldt-Jakob disease established by experimental transmission to primates. ${ }^{16}$ This report adds to the wide range of presenting features of Creutzfeldt- 
Jakob disease. Stroke-like episodes and transient ischaemic-like attacks often referable to the posterior fossa are other unusual presentations, ${ }^{16}$ and as mentioned before may occur in the absence of clinical dementia. The rapid, progressive course with ensuing myoclonus should alert one to the diagnosis. Thus knowledge of the different presentations of Creutzfeldt-Jakob disease, often without the full classic triad of ataxia, dementia, and startle myoclonus, may be important with increased public awareness of the condition.

We thank Dr Fred Plum for his comments and review of this paper.

1 Brion S, Jedynak C-P. Trouble du transfert interhemispherique a propos de trois observations de tumeurs du corps calleux: le signe de la main etrangere. Rev Neurol 1972;126:257-66.

2 Akelaitis AJ. Studies on the corpus callosum. IV. Diagonistic dyspraxia in epileptics following partial and complete section of the corpus callosum. Am $\mathcal{F}$ Psychiatry 1944-5; 101:594-9.

3 Bogen JE. The callosal syndromes. In: KM Heilman, E Valenstein, ed. Clinical Neuropsychology. 2nd ed. Oxford: Oxford University Press, 1985:295-338.

4 Goldberg G, Mayer NH, Toglia JU. Medial frontal cortex infarction and the alien hand sign. Arch Neurol 1981;38: 683-6.

5 McNabb AW, Carroll WM, Mastaglia FL. "Alien hand" and loss of bimanual coordination after dominant anterior cerebral artery territory infarction. $\mathcal{F}$ Neurol Neurosurg Psychiatry 1988;51:218-22

6 Banks G, Short P, Martinez J, Latchaw R, Ratcliff G, Boller F. The alien hand syndrome. Clinical and postmortem findings. Arch Neurol 1989;46:456-9.

7 Tanaka Y, Hideaki I, Yoshida M. Diagonistic dyspraxia: case report and movement-related potentials. Neurology 1990; 40:657-61.

8 Starkstein SE, Berthier ML, Fedoroff P, Price TR, Robinson RG. Anosognosia and major depression in 2 patients with cerebrovascular lesions. Neurology 1990;40:1380-2.

9 Feinberg TE, Schindler RJ, Flanagan NG, Haber LD. Two Feinberg TE, Schindler RJ, Flanagan NG, Haber

10 Trojano L, Crisci C, lanzillo B, Elefante R, Caruso G. How many alien hand syndromes? Follow up of a case. Neurology 1993;43:2710-2.

11 Uchiyama S, Yoshino K, Ohka T, Uchiyama C. The alien hand sign associated associated with left anterior cerebra artery occlusion. Neurol Med (Tokyo) 1983;18:396-9. (In Japanese.)
12 Rinne JO, Lee MS, Thompson PD, Marsden CD. Corticobasal degeneration. A clinical study of 36 cases. Brain 1994;117:1183-96.

13 Ball JA, Lantos, Jackson M, Marsden CD, Scadding JW, Rossor MN. Alien hand sign in association with Alzheimer's histopathology. $\mathcal{F}$ Neurol Neurosurg Psychiatry 1993;56: 1020-3.

14 Green RC, Goldstein FC, Mirra SS, Alazraki NP, Baxt JL, Bakay RAE. Slowly progressive apraxia in Alzheimer's disease. 7 Neurol Neurosurg Psychiatry 1995;59:312-5.

15 Mastrianni J, Iannocola C, Myers RM, DeArmond S, Prusiner SB. Mutation of the prion protein gene at codon 208 in familial Creutzfeldt-Jakob disease. Neurology 1996; 47:1305-12.

16 Brown P, Gibbs CJ, Rodgers-Johnson P, Asher DM, Sulima MP, Bacote A, et al. Human spongiform encephalopathy: the National Institutes of Health series of 300 cases of experimentally transmitted disease. Ann Neurol 1994;35: 513-29.

17 Hsich G, Kenney K, Gibbs CJ, Lee KH, Harrington MG. The 14-3-3 brain protein in cerebrospinal fluid as a marker for transmissible spongiform encephalopathies. New Engl f Med 1996;335:924-30.

18 Taraboulos A, Jendroska K, Serban D, Yang SL, DeArmond SJ, Prusiner SB. Regional mapping of prion proteins in brain. Proc Natl Acad Sci USA 1992;89:7620-4.

19 Riley DE, Lang AE, Lewis A, Resch L, Ashby P, Hornykiewicz O. Cortico-basal ganglionic degeneration. Neurology 990;40:1203-12.

20 Gibb WRG, Luthert PJ, Marsden CD. Corticobasal ganglionic degeneration. Brain 1989;112:1171-92

21 Doody RS, Jankovic J. The alien hand and related signs. $f$ Neurol Neurosurg Psychiatry 1992;55:806-10.

22 Geschwind DH, Iacobini $M$, Mega MS, Zaidel DW, Cloughesy T, Zaidel E. Alien hand syndrome: interhemispheric motor disconnection due to a lesion in the midbody of the corpus callosum. Neurology 1995;45:802-8.

23 Leiguardia R, Starkstein S, Berthier M. Anterior callosal hemorrhage. A partial interhemispheric disconnection syndrome. Brain 1989;112:1019-37.

24 Pandya DN, Karol EA, Heilbronn D. The topographical distribution of interhemispheric projections in the corpus callosum of the rhesus monkey. Brain Res 1971;32:31-43.

25 Dolado AM, Castrillo C, Urra DG, Varela De Seijas E. Alien hand sign or alien hand syndrome? $f$ Neurol Neurosurg Psychiatry 1995;59:100-1.

26 Leiguardia R, Starkstein S, Nogues M, Berthier M, Arbelaiz R. Paroxysmal alien hand syndrome. I Neurol Neurosurg Psychiatry 1993;56:788-92.

27 Levine DN, Rinn WE. Opticosensory ataxia and alien hand syndrome after posterior cerebral artery territory infarction. Neurology 1986;36:1094-7.

28 Decety J, Perani D, Jeannerod M, Bettinardi V, Tadary B, Woods $\mathrm{R}$, et al. Mapping motor representations with positron emission tomography. Nature 1994;371:600-2.

29 Ventura MG, Goldman S, Goldman S, Hildebrand J. Alien hand syndrome without a corpus callosum lesion. $\mathcal{F}$ Neurol Neurosurg Psychiatry 1995;58:735-7. 